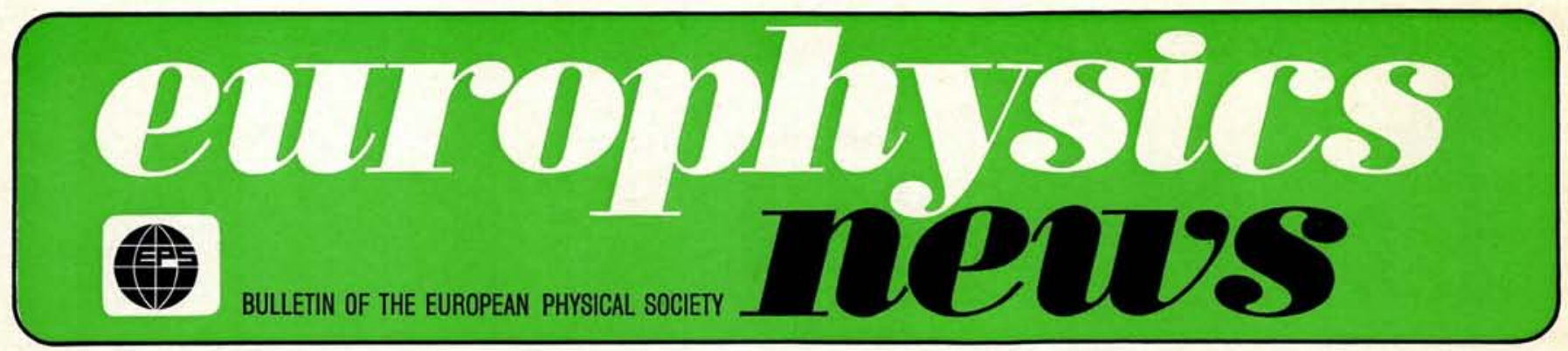

\section{Outlook for Physics}

Victor F. Weisskopf gives his views on the outlook for physics in an interview with the Editor of Europhysics News, Alex H. Crawford, at CERN, Geneva, in August 1973.

- It is often said that what is happening in the United states now will occur in Europe and the rest of the world later. Is this true of the decline in support for physics, in your view, Prof. Weisskopf?

- To some extent, it is true. However, I believe that there are significant differences. Events in Europe usually are delayed and damped when compared with those in the States. We should expect some some decline in support for basic science in Europe, but it should not be as abrupt nor as virulent as that in the United States. Of course, one might say that, because the peaks were higher in the United States, a deeper drop can be afforded there. Also, it is worth pointing out that Europe has pulled itself up in the past decade in all branches of science and, therefore, policy makers in Europe have become aware more recently of the values of basic science, so that it is not likely to suffer as much as it has in the United States.

But I must point out one danger that I see for European science. In the United States, physicists have been involved greatly in the solution of practical problems - environmental, industrial, and, I hate to say, military. European physicists, howver, have been less involved in such activities and this has made them appear to be less concerned with current societal problems. There seems to be a misplaced puritanism in Europe in not wanting closer connection with governments, on the grounds that not all of their activities are approved. Some blame also attaches to the governments, because they do not seek out the physicists who might help them. It seems that there

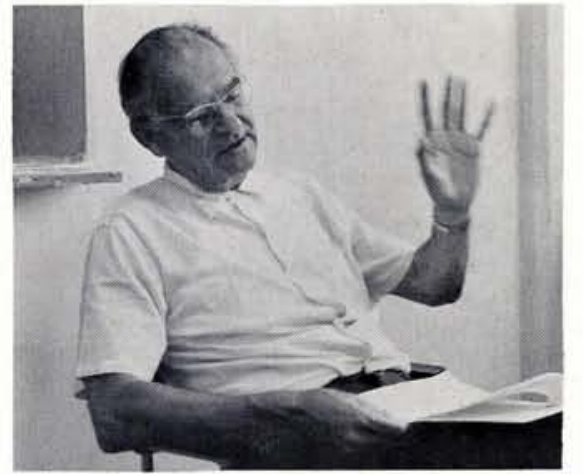

"But I must point out one danger... There seems to be a misplaced puritanism in Europe..."

is not so much give and take in Europe between the governments and the physicists. More involvement by physicists in environmental and industrial problems is desirable and would be helpful in avoiding a sharp decline of support for basic science in Europe. It is true that the closer relations in the USA have not prevented serious cuts; I believe, however, that the cuts would have been worse without those relations.

- June 1972 saw the completion of report by the Physics Survey Committee on Physics in Perspective for the National Academy of Sciences in the United States. You were a member of the Survey Committee. Were there any new approaches in this important science policy document which might be worthy of adoption in Europe?

- The report set out to describe in depth the value and breadth of physics. Varied reasons for support of the different sub-fields of physics were given, and I believe these provided good weapons against the general trend to remove emphasis from the basic sciences. From this aspect, Physics in Perspective might be useful in Europe. However, it did not make any radical suggestions for changes in the conduct of physics. - How, in fact, was the Physics in Perspective report received by

(a) physicists in general,

(b) science policy makers in the United States, and

(c) the public-at-large?

- Although the report was well received, there was some disappointment at the lack of strength of its impact. There was very little criticism from physicists. Science policy makers certainly read it carefully. Some commentators were critical because they said the report was "selfserving". Well, of course it was "selfserving". One could hardly expect anything else from a report of that nature - the criticisms would have carried more weight if they had dealt with whether the arguments in it for support of physics were good or bad. Physics in Perspective was not aimed at the public-at-large, but reviews that appeared were relatively positive.

- The Office of Science and Technology in the United States was closed down this year and the Director of the National Science Foundation was appointed as Science Advisor. Did this change imply the demise of basic science as an influence on government, as some commentators have hinted?

- Yes, it did, but not so dramatically as your question implies. The influ-

\section{Contents}

Outlook for Physics

Industrial Research

Manager

Impact Ionization

Controlled Fusion and

Plasma Physics.

Society News

Meetings

1
4
6
6
7
8




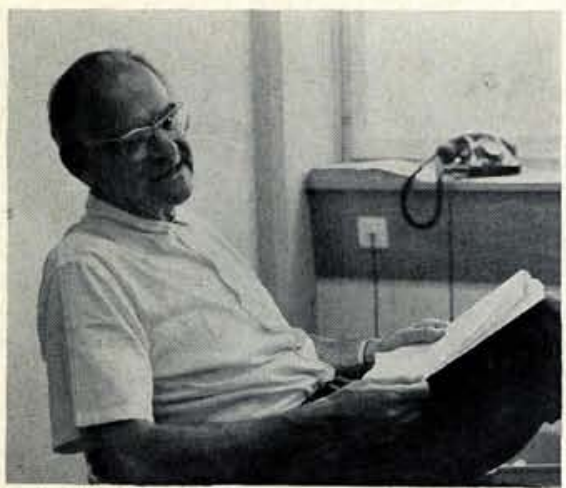

"Science has even pilloried as the criminal !"

ence of basic science on government has been greatly reduced, but it does not amount to a complete demise, since budgets are still relatively large. For example, the United States has just completed construction of the largest high energy physics machine in the world. It is true that support for basic science is going down. The beneficial contributions of science are overlooked and the abuses, such as the war applications and the pollution of the environment, are emphasized. The seamy sides of our technoligical civilisation are highlighted, but the good, productive aspects are forced into the shadows in this decade. Science has even been pilloried as the criminal! This is all part of a process of oversimplification, and of the need for a scapegoat. Things are much more complicated than they appear; although the atomic bomb must be viewed as a devilish invention, it may have guaranteed the longest period of peace that Europe has ever known.

- Apparently, pay-off and relevance are criteria stressed in allocation of funds for research in the United States. How have the different subfields of physics fared?

- This is an interesting question. Since immediate pay-off and visible, practical importance were to be the criteria stressed, the expectation was that the more basic fields would have fared worse. But all subfields have been cut roughly the same - solid state physics almost as much as high energy physics. A short-sighted approach has been applied with some naivety. We can only hope for future changes and be satisfied that the funding curve has not gone down more steeply than it has.

- In May 1973, the Cambridge Electron Accelerator closed down, and this followed the closure of the Brookhaven Cosmotron and the Princeton Pennsylvania Accelarator. What, in fact, does the future hold for high energy physics in the United States? - When you see the signs of obsolescence, then closing down is not necessarily bad. The difficulty is to decide when. In periods of affluence, the installations may be closed down too late. Now, in a period of stress, it may be that installations have been closed down too early. However, closure of installations may be a sign of health, if new ones are made available - and, there is one positive element to be noted: the National Accelerator Laboratory (NAL) has been approved and will be

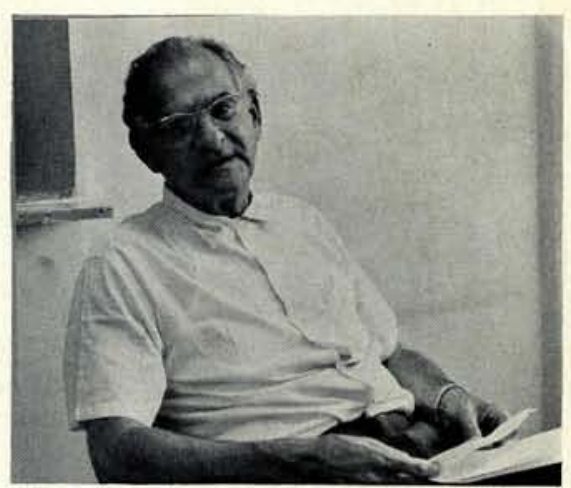

"A short-sighted approach has been applied with some naivety.

reasonably well supported. The future programme is more questionable, because of the decline in public support. However, the American high energy physicists keep on proposing new ideas, such as

(a) the doubling of energy at SLAC ;

(b) the PEP proton-electron-positron storage ring at Stanford and Berkeley, and the ISABELLE proton-proton storage ring at Brookhaven ;

(c) an increase in energy and, possibly, storage rings at NAL.

Physicists in the United States continue to have wide discussions on such proposals, but their realisation is questionable in the near future.

The problems of the planning of future high energy installations are similar in the United States and in Europe. The facts that NAL in the United States and the Super Proton Synchrotron at CERN have been approved make it difficult to speak of

\section{F. WEISSKOPF}

Victor F. Weisskopf was born on 18 September 1908 in Vienna. He learned physics from Hans Thirring at Vienna University, before moving to the University of Göttingen where there were teachers such as M. Born, J. Frank, W. Heitler, G. Herzberg, P. Jordan and E.P. Wigner. He obtained his Ph.D. at Göttingen in 1931 for work on the natural width of spectral lines. There followed periods of collaboration with W. Heisenberg and F. Schrödinger in Germany, L.D. Landau, E.M. Lifshitz and Achiezer in USSR, N. Bohr in Denmark, P. Dirac in the UK, and W. Pauli in Switzerland, before Weisskopf took up an intructor position at the University of Rochester in the USA in 1937. In 1943, he accepted an invitation from R. Oppenheimer to join the group of physicists at Los Alomos to develop the atomic bomb. In 1946, Weisskopf became Professor of Physics at the Massachusetts Institute of Technology, where he is now Head of the Department of Physics.

In 1950, Weisskopf was the first professeur étranger at the Sorbonne; then, for five years from 1960-65, he was Director-General of CERN. He joined CERN after its initial years of construction and administrative organisation were complete, and so was able to concentrate on building up an atmosphere of research activity. One of Weisskopf's most important contributions to the development of CERN was his insistence on the construction of the Intersecting Storage Rings, approved at the last CERN Council meeting which he chaired in 1965 . He still works during the summer months each year at CERN and, officially, is a member of its Scientific Policy Committee.

Apart from his membership of the National Academy of Sciences in the USA, Weisskopf is a corresponding member of the following European bodies: Academy of Sciences of the Institute of France ; Austrian Academy of Sciences; Bavarian Academy of Sciences ; Royal Society of Edinburgh ; Spanish Academy of Sciences; The Royal Danish Academy of Sciences and Letters. $\mathrm{He}$ is an honorary member of the French Physical Society.

$\mathrm{He}$ is presently working on several survey articles on modern physics, on a book on Qualitative Physics, on a revised version of his book Knowledge and Wonder, and is looking forward to the appearance of French and German translations of his recent volume of selected essays Physics in the Twentieth Century. 
future plans, in view of the vast commitments made. However, if we wish to progress, it is important to keep on discussing future projects from all aspects - physics, economics, politics. This is traditional in the United States, and I hope that European physicists take up discussions of future facilities in all fields of physics with as much vigour as in the past. Although such discussions might give the impression that physicists were insatiable, not to engage in them would make it appear that there was no future.

Another trouble with devising ambitious new projects is that other physicists might become jealous - and an anti-high-energy-physics feeling is already apparent. However, I believe that it is unjustified. If one part of physics is well supported, then, in the long run, other parts profit, as past history has shown. If one part of physics is slowed down, the money saved is hardly ever transferred to another part.

- Physicists in both the United States and Europe have become increasingly concerned with their obligations to society. Is this trend likely to lead anywhere, or should physicists keep their political activities quite separate from their discipline?

- This question is based on a misunderstanding. There is no difference betwen activities as a scientist and obligations to society. As long as science is seen as the quest for knowledge, then a physicist carries out obligations to society by engaging in this quest. However, these obligations are various, and scientists must guard against over-specialization. Scientists should also contribute to problems usually called more practical. A science like physics has many sides and is in many ways involved in the cultural and social life of mankind. As I wrote in my book Physics in the Twentieth Century :

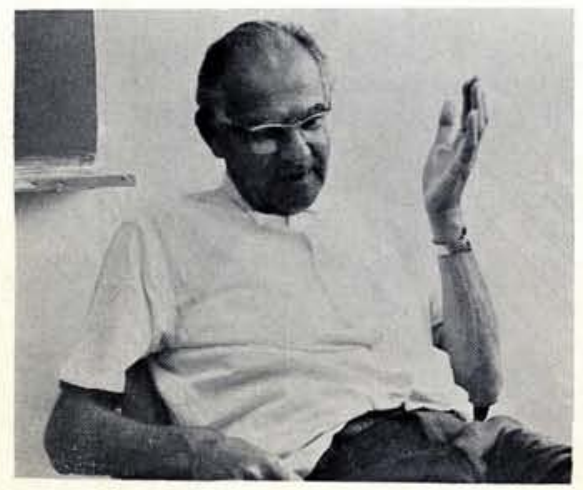

“... an anti - high - energy - physics feeling is already apparent."

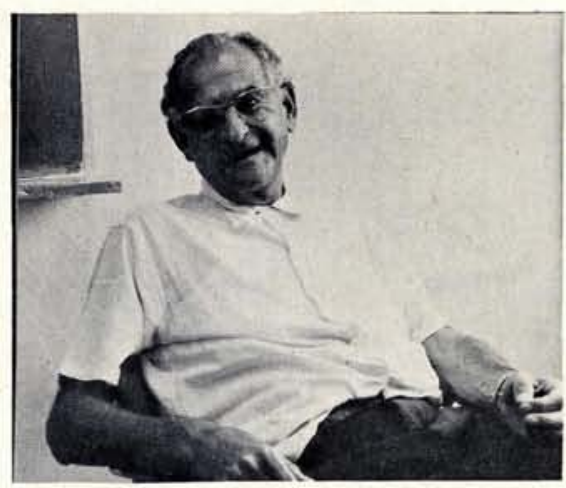

"... any national goal which is not also an international one is automatically invalid."

"Science cannot develop unless it is pursued for the sake of pure knowledge and insight. It will not survive unless it is used intensely and wisely for the betterment of humanity."

- More and more physics is funded apparently because of its contribution to national goals. How do you resolve the inherent conflict that this brings about with the international nature of physics as a discipline?

- There is no conflict, since any national goal which is not also an international one is automatically invalid. Nations should be viewed just as administrative sub-divisions of world society.

- Do you think that physics does enough to communicate with the public-at-large?

- Physicists do not do enough, certainly. They see popular writing and similar activities as a secondary duty, definitely less important than research. Perhaps I should quote again from Physics in the Twentieth Century:

"Much more could and should be done to bring the fundamental ideas nearer to the intelligent layman. Popularization of science should be one of the prime duties of a scientist.

A lucid and impressive presentation of some aspect of modern science is worth more than a piece of so-called original research of the type found in many Ph.D. theses, and it may require more maturity and inventiveness.

Furthermore, it is beneficial to the scientist to attempt seriously to explain his scientific work to a layman or even to a scientist in another field. Usually, if one cannot explain one's work to an outsider, one has not really understood it. More concerted and systematic effort toward presentation and popularization of science would be helpful in many respects; it would provide a potent antidote to overspecialization ; it would bring out clearly what is significant in current research ; and it would make science a more integral part of the culture of today."

More should be done to encourage young people to go in for science writing. Science writers should be invited to physics meetings; their social standing in the scientific society must be raised.

In addition, physicists should not underestimate the public. It is much more interested in basic science than many of us assume. Basic science corresponds to a deep craving many feel - to know about the origin of matter, the origin and the development of the universe, about the laws that govern the natural world, and about the fundamental units of which matter is composed. Often these basic subjects are of more interest to the public than problems of practical significance.

- You were one of the Plenary Lecturers at the First General Conference of the European Physical Society in Florence in April 1969. What part would you consider the Society shoud play in promoting the advancement of physics in Europe and neighbouring countries?

- One thing that occurs to me immediately is that the European Physical Society could encourage good science writing.

- Finally, Prof. Weisskopf, how would you sum up your own personal goals in physics at the moment?

- The 45 years I have spent in physics have been extremely interesting and gratifying. It is my aim to keep on portraying the excitement of physics and bringing an awareness of its philosophical significance both to the physics community and to the outside. I hope to keep in touch with trends, general and particular, and to help furthering communication with the public-at-large and amongst physicists themselves. It is perhaps not unnecessary to state that I find physics today just as interesting as it was when I was a student in the 20s. I find excitement and challenge in the new discoveries being made now, no less than in the theoretical insights then.

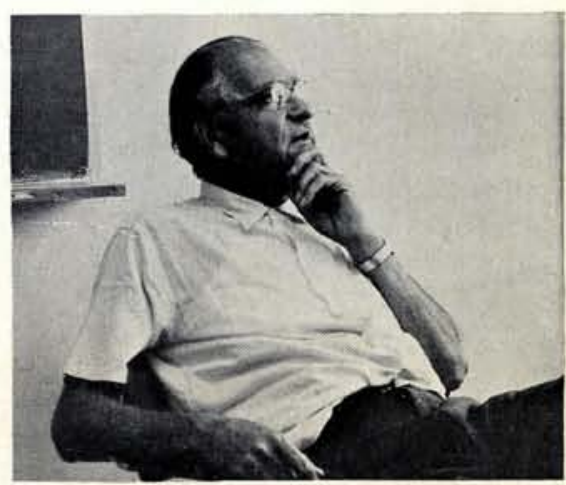

"Basic science corresponds to a deep craving many feel..." 